\title{
Habitat quality and breeding parameters in relation to female mating status in the polygynous Eurasian Bittern Botaurus stellaris
}

\author{
Zbigniew Kasprzykowski • Marcin Polak
}

Received: 8 February 2011/Revised: 6 September 2012/Accepted: 8 October 2012/Published online: 26 October 2012

(C) The Author(s) 2012. This article is published with open access at Springerlink.com

\begin{abstract}
The Eurasian Bittern Botaurus stellaris has a polygynous mating system where the nests of solitary and clumped females are located within a male territory. However, the factors that may favour the formation of nest clusters remain unknown. The focus was on the clustering effect in the Eurasian Bittern population on fishpond complexes in eastern Poland in order to test whether clumped nesting is dependent on habitat quality. Breeding parameters were also assessed in order to investigate the advantages accruing to females of nesting close together in clusters. During the breeding periods between 2003 and 2009, we found 144 active nests of the Eurasian Bittern: most of them (55.5\%) were in clusters of two to four nests. The mean distance between adjacent nests in a cluster was $23.5 \mathrm{~m}$. The proportion of open water to emergent vegetation and the category of fish stock have significant effects on cluster nesting in the Eurasian Bittern. There were differences between single and clumped nests with respect to the first-egg laying date and male presence. The environmental and ecological factors that may determine the Eurasian Bittern female's nest-site choice are discussed.
\end{abstract}

Keywords Ardeidae - Breeding strategy · Fishponds · Nesting habitat · Polygyny

Communicated by T. Gottschalk.

Z. Kasprzykowski ( $\square)$

Department of Ecology and Environmental Protection, University of Natural Sciences and Humanities in Siedlce, Prusa 12, 08-110 Siedlce, Poland

e-mail: zbykas@uph.edu.pl

\section{Polak}

Department of Nature Conservation, Maria Curie-Skłodowska University, Akademicka 19, 20-033 Lublin, Poland

e-mail: mpolak@hektor.umcs.lublin.pl

\section{Zusammenfassung}

Habitatqualität und Brutparameter in Bezug auf den weiblichen Paarungsstatus bei der polygynen Rohrdommel Botaurus stellaris

Die Rohrdommel Botaurus stellaris hat ein polygynes Paarungssystem, wo die Nester von einzeln und in Clustern nistenden Weibchen innerhalb des männlichen Territoriums liegen. Die Faktoren, welche die Bildung von Nestclustern fördern können, sind jedoch unbekannt. Der Schwerpunkt unserer Studie lag darauf, den Clustereffekt in einer Rohrdommelpopulation an Fischteichen in Ostpolen zu untersuchen und zu testen, ob das Nisten in Clustern von der Habitatqualität abhängig ist. Brutparameter wurden ebenfalls abgeschätzt, um die Vorteile zu untersuchen, die sich Weibchen bieten, welche nah beieinander in Clustern nisten. Während der Brutperioden zwischen 2003 und 2009 fanden wir 144 aktive Nester der Rohrdommel; die meisten $(55,5 \%$ ) befanden sich in Clustern von zwei bis vier Nestern. Die durchschnittliche Entfernung zwischen angrenzenden Nestern in einem Cluster betrug 23,5 m. Das Verhältnis von offenem Wasser zu schwimmender Vegetation sowie die Kategorie des Fischbestandes haben bei der Rohrdommel signifikante Effekte auf das Nisten in Clustern. Einzelne Nester und Nester in Clustern unterschieden sich bezüglich des Legedatums des ersten Eies und der Anwesenheit von Männchen. Die Umweltfaktoren und ökologischen Faktoren, welche die Nistplatzwahl weiblicher Rohrdommeln bestimmen können, werden diskutiert.

\section{Introduction}

The Eurasian Bittern Botaurus stellaris differs from other herons (Ardeidae) in many aspects of its ecology 
(Voisin 1991; Kushlan and Hafner 2000). This is a little known, solitary and secretive reedbed species which has a polygynous mating system. Females do not normally receive help from males in the care of the young (Gauckler and Kraus 1965; Cramp and Simmons 1977; Puglisi and Bretagnolle 2005; but see Klejdus 2007). Eurasian Bitterns are reported to nest on wet vegetation stands with rich food resources such as fish, crustaceans, amphibians and insects (Gilbert et al. 2003; Poulin et al. 2005; Puglisi and Bretagnolle 2005), and in related open habitats, especially highly productive marshlands, which can be monopolised by certain males; these then attract additional females to their high quality territories (Verner and Willson 1966). However, in Eurasian Bitterns, some female nest sites may not coincide with the locations of male booming territories (Gauckler and Kraus 1965; Adamo et al. 2004; Gilbert et al. 2005a; White et al. 2006). The distribution of food resources and suitable nest sites (dense vegetation with an appropriate water level) may determine the distribution of females, which collect food alone and usually in close proximity to the nest (Puglisi et al. 2003; Adamo et al. 2004). As a result of this clustering of females, some males may have easier access to more than one female (resource defence polygyny; see Ostfeld 1987; Dyrcz and Zdunek 1993; Jiguet et al. 2000). However, the factors that may influence female nest grouping in Eurasian Bitterns remain unknown.

The aim of this paper is to characterise the clumped nesting system in a Eurasian Bittern population on fishponds. The ecosystem of a fishpond complex, with different nest-site vegetation types and different fish stocks in particular ponds, provides a good opportunity to study the clustering effect. The first hypothesis to be tested was that clumped nesting depends on habitat quality. It was expected that females would prefer to nest in attractive habitats offering rich food resources and suitable nesting sites. The second hypothesis was that females nesting close together in clusters are more successful than females on isolated nests. Because of the lack of or only occasional male parental care (Voisin 1991; Klejdus 2007), female reproductive success in Eurasian Bitterns may be much more dependent on territory and/or maternal quality than in other frequently studied species (Forstmeier et al. 2001; Moreno et al. 2002).

The Eurasian Bittern is an important target species for wetland conservation in many European countries, and different types of conservation projects have been drawn up and implemented. Habitat management, the main aim of these projects, should be undertaken only when sufficient knowledge of the ecology of the sites has been gained (White et al. 2006). The results of this study may provide useful guidelines for management planning in existing breeding sites and to restore the appropriate habitat components of future Eurasian Bittern nesting areas.

\section{Methods}

Study sites

The study was carried out on 15 fishpond complexes situated in eastern Poland $\left(50^{\circ} 55^{\prime}-52^{\circ} 11^{\prime} \mathrm{N}, 21^{\circ} 58^{\prime}-22^{\circ} 54^{\prime} \mathrm{E}\right)$. The ponds varied in area from 15 to 203 ha, covering a combined total of 1,115 ha. In this kind of extensively managed fish farming, the most abundant species stocked was Common Carp Cyprinus carpio. Most ponds were partially covered by discrete stands of vegetation dominated by Common Reed Phragmites australis. In eastern Poland, fish farms with dense, small-bodied fish populations and a large coverage of only occasionally cut emergent vegetation have a bird-friendly fish management and may still support a relatively high waterbird species richness. For a detailed description of the habitat, see Polak et al. (2008). The density of the Eurasian Bittern breeding populations in the study area ranged between 1.1 and 12.5 inds/100 ha for males, and between 1.1 and 20.0 inds/ 100 ha for females; this is the largest density recorded in Poland (Polak and Kasprzykowski 2009). The extensive fish management and abundant food resources were most likely responsible for the good breeding parameters obtained for this population (Polak and Kasprzykowski 2010).

\section{Field procedures}

Potential nest sites were surveyed throughout the breeding period, from the end of April to early July during 2003-2009. Nests were located by systematically wading through patches of emergent vegetation covering from 0.03 to 4 ha. Most nests were found in the egg-laying period or the incubation period (121), and the remainder in the nestling period (23). Because the nesting period in eastern Poland is short, we did not find any double broods. All the clutches laid in late May in our study area were probably replacement clutches (Dmitrenok et al. 2005), but after the loss of the original clutch, they were not laid in the same cluster. Nests were inspected regularly (mean 4 inspections, range 1-9) and special attention was paid to finding nest clusters. With this aim in mind, the surroundings of every nest found were searched: in a large reedbed, this was the area within a radius of $100 \mathrm{~m}$ from the nest. The distances between the nearest active nests were measured at 1-m intervals using a tape or GPS. During each visit to the study area, all call-locations of males were plotted on a 1:5000 map. Special attention was paid to recording the position of simultaneously active birds on a cumulative map, and the borders of booming sites of individual males were delimited by use of the minimum convex polygon method (Kenward 1987). A territory was treated as occupied 
Table 1 Habitat variables and breeding parameters taken into consideration in this study of the effect of clustered nesting in Eurasian Bitterns Botaurus stellaris

\begin{tabular}{ll}
\hline Code & Meaning \\
\hline WATER & Estimated water depth $(\mathrm{cm})$ at the centre of the plot with 1-cm precision \\
OLD & Number of dry reed stems within a $50 \times 50 \mathrm{~cm}$ square \\
NEW & Number of green reed stems within a $50 \times 50 \mathrm{~cm}$ square \\
DISTOW & Distance $(\mathrm{m})$ to open water pool \\
DISTDYKE & Distance $(\mathrm{m})$ to the fishpond dyke \\
PROARE & Proportion of open water area (ha) to emergent vegetation area (ha) \\
& on a given fishpond \\
PATCH & Patch of emergent vegetation with active nests (random factor) \\
CARP & Category of fish stocks: $0=$ young-of-year (0) carp with individual \\
& weights of $1.5-3.0$ mg, to reach $8-15 \mathrm{~g}$ in early July; $1=$ medium \\
& carp after first wintering at $30-50 \mathrm{~g} ; 2=2$-year-old-carp \\
& at $150-240 \mathrm{~g} ;$ and $\mathrm{W}=$ wild or fish ponds, with different species \\
and different age categories \\
FLEDG & Standardised first-egg laying date \\
SUCCESS & The number of 15 -day nestlings (fledglings) \\
MALE & Nests where at least one young bird had survived up to 15 days \\
& old: $0=$ without success, 1 = with success \\
& Nests located within the male booming area: $0=$ outside \\
& (male absent), $1=$ inside (male present)
\end{tabular}

when three occurrences of one male in the same patch of vegetation were noted.

Habitat measurements were performed using the methodology applied in studies of the Eurasian Bittern in the UK (Tyler et al. 1998; Gilbert et al. 2005a) with some modifications (Table 1). Six different habitat variables were analysed: water depth (WATER); two microhabitat variables: the number of dry (OLD) and green (NEW) reed stems within a nest square; and three macrohabitat variables: the distance to open water (DISTOW), the distance to the fishpond dyke (DISTDYKE) and the proportion of open water area to emergent vegetation area (PROARE). Providing a very good description of the Eurasian Bittern's habitat preferences, these variables may determine some of this species' breeding parameters in a specific semi-natural habitat like fishponds (Polak 2007; Polak et al. 2008). In particular; the proportion of open water area to emergent vegetation area is a much better habitat descriptor of a fishpond than other macrohabitat components like water edge, which are important for populations living in more natural habitats. All the measurements were made from the end of April to the end of May. The microvariables were measured in $0.25-\mathrm{m}^{2}$ quadrats placed around the nests, whereas the macrovariables were measured from aerial photographs (GEOPORTAL, www.geoportal.gov.pl). Four categories of fish stocks (CARP), which described the richness of food resources, were treated as qualitative predictors. In accordance with Kloskowski (2009), we divided Common Carp into 3 year classes in separate ponds (Table 1).

Two types of nests were distinguished: single (no cluster effect) and clumped. The category of clumped nests refers to the nests located close to one another within a separate patch of emergent vegetation, i.e. one that is situated on one pond and surrounded by open water and/or the fishpond dyke. The following breeding parameters were analysed: the first-egg laying date (EGGDATE), the number of 15-day nestlings (FLEDG) and nest success (SUCCESS). Because 2-week-old Bitterns can disperse from the nest into the dense vegetation, nests were defined as being successful when at least one young bird had survived up to 15 days old (after Puglisi and Bretagnolle 2005). To eliminate the year effect, the data were standardised against the median of the first egg date in the population in each year. Some nests $(29 \%)$ were located during the egg-laying period, but in the majority of nests the first-egg laying date was established by backdating, assuming 25-26 days for incubation (Cramp and Simmons 1977; Mallord et al. 2000; Demongin et al. 2007).

\section{Statistical analysis}

The relationships between the clustering effect in the Eurasian Bittern and the variables were modelled using a generalised linear mixed modelling (GLMM) procedure. Two models were constructed, in which single nests and clumped nests were treated as a binomial dependent variable $(0=$ lack of cluster effect, $1=$ nest situated in cluster). Six different habitat variables and categories of fish stock were included in the first model. The second model tested the null hypothesis that single and clumped nests did not differ in the following breeding parameters: the first-egg laying date, the number of fledglings and nest success. Because male parental care was not excluded, allowance was made for the situation where nests were 
recorded within or outside booming sites: male present or absent (MALE). In both models, the patch of emergent vegetation with active nests was used as a random factor.

Akaike's information criterion (AIC) was used to evaluate which of the models was best supported by the data (Burnham et al. 2011). Only the models with AIC $<2$ are discussed, because they are regarded as being equally supported. The models with the lowest AIC value were selected as the best fitting models. Statistical processing was performed using the STATISTICA 9.0 package (Statsoft 2011).

\section{Results}

Of the 144 nests found, $80(55.5 \%)$ were built in close proximity to one another in one patch of vegetation, forming a cluster. Most clusters contained two nests $(n=24)$, fewer had three nests $(n=8)$, and only two clusters consisted of four nests. The mean distance between adjacent clumped nests was $23.5 \mathrm{~m}(\mathrm{SD}=21.28$, range $3-108, n=76)$, and most nests $(75 \%)$ were situated less than $30 \mathrm{~m}$ from one another (Fig. 1).

In the first analysis, of the 127 combinations of variables investigated, the model containing the number of green reed stems, the proportion of open water to emergent vegetation and the category of the fish stock (with no interaction) best explained clustered nesting in the Eurasian Bittern (Table 2). The four subsequent models included all these variables and additionally one different predictor. A GLMM model was therefore constructed with just these three variables, each having a different influence on the probability of clumped nesting (Table 3). The number of green reed stems did not have a significant effect, but in the squares with clustered nests there were $50 \%$ more green reed stems than where females were nesting singly (Table 4). The proportion of open water to emergent vegetation had a significant influence on the probability of nesting in clusters: clumped females preferred a more even proportion of these two habitats than

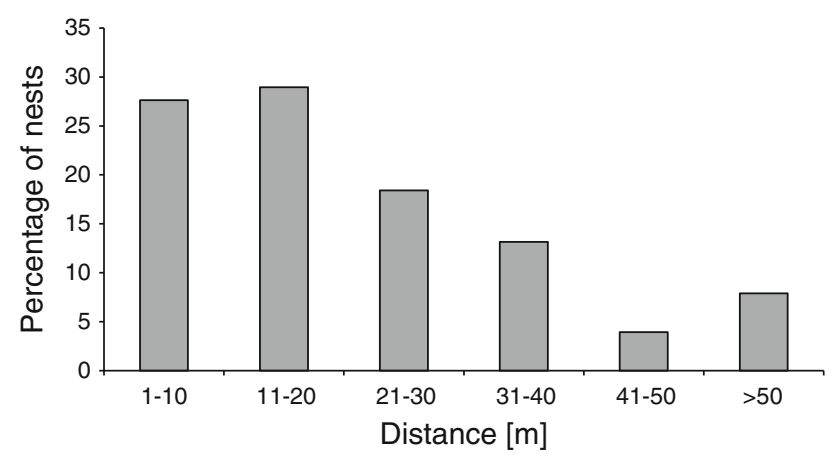

Fig. 1 Distance between Eurasian Bittern Botaurus stellaris nests within clusters $(n=76)$ single-nesting females (Table 4). The third predictor with a significant effect on clumped nesting was fish stock. Ponds with young-of-year carp $(0+)$ were sparsely populated by clustering females. On the other hand, ponds with the medium year-class $(1+)$ were clearly more attractive for colonisation, and $70 \%$ of clumped nests were recorded in this category of pond (Fig. 2). The other two categories -ponds with 2-year-old carp $(2+)$ and wild fishponds (W) -were of minor importance.

For the second analysis, where breeding parameters in 63 different variations were analysed, the selected model included two variables: the first-egg laying date and the presence of a male booming site (Table 2). As in the first analysis, these two variables were included in the best and subsequent models. Two categories of nests differed significantly in the first-egg laying date (Table 3). In single nests, the first eggs were laid 5 days earlier than in the clustered nests, and the first-egg laying period (53 days) was longer in nest clusters than in single nests (47 days). The presence of males in the nesting habitat was also significant. In male territories, there were more clumped nests $(97.5 \%)$ than single ones $(69.6 \%)$. Neither the number of fledglings nor nest success was taken into consideration as differences between single and clumped nests.

\section{Discussion}

The study shows that clumped nesting is a common strategy in the population of the Eurasian Bittern in the fishponds of eastern Poland. In different European populations, from one to five female nests have been found within male territories (Gauckler and Kraus 1965; Puglisi and Bretagnolle 2005), but nest clusters have only occasionally been reported (White et al. 2006). The high percentage of clumped nests (55\%) may be explained by the good breeding habitats and food resources in the fishpond complexes studied (Polak and Kasprzykowski 2010).

Only one of the six habitat variables analysed, the ratio of emergent vegetation area to open water area, is clearly important to clumped females. The mean value of this parameter was lower for nests in clusters than for single nests. Both habitat components (emergent vegetation and open water) are probably key factors with regard to the richness of potential prey items and nesting preferences. In fishpond ecosystems, the prey fed to Eurasian Bittern nestlings by females consists mostly of fish (Polak 2007). A suitable proportion of fish fry habitat (open water) and Eurasian Bittern breeding habitat (reedbeds) in a seminatural ecosystem seems optimal for the polygynous system of reproduction. Habitat use by the Eurasian Bittern population in this study was corroborated by studies carried 
Table 2 Model selection using Akaike's information criteria (AIC) to determine the effect of habitat variables (Model 1) and differences in breeding parameters (Model 2) on clumped nesting of Eurasian Bitterns

\begin{tabular}{|c|c|c|c|c|c|}
\hline Variables & AIC & $\Delta \mathrm{AIC}$ & AICwt & $\mathrm{k}$ & $\mathrm{D}$ \\
\hline \multicolumn{6}{|l|}{ Model 1} \\
\hline NEW + PROARE + CARP & 155.49 & 0.00 & 0.226 & 3 & 41.659 \\
\hline WATER + NEW + PROARE + CARP & 157.24 & -1.75 & 0.092 & 4 & 41.861 \\
\hline DISDYKE + NEW + PROARE + CARP & 157.33 & -1.84 & 0.089 & 4 & 41.791 \\
\hline OLD + NEW + PROARE + CARP & 157.35 & -1.86 & 0.088 & 4 & 41.776 \\
\hline DISTOW + NEW + PROARE + CARP & 157.49 & -2.00 & 0.084 & 4 & 41.680 \\
\hline \multicolumn{6}{|l|}{ Model 2} \\
\hline EGGDATE + MALE & 116.13 & 0.00 & 0.362 & 2 & 25.487 \\
\hline EGGDATE + FLEDG + MALE & 117.98 & -1.85 & 0.143 & 3 & 25.633 \\
\hline EGGDATE + MALE $+1 \times 2$ & 118.09 & -1.96 & 0.136 & 3 & 25.524 \\
\hline
\end{tabular}

$\triangle A I C$ Delta Akaike's information criteria, AICwt AIC weight, $k$ number of parameters, and $D$ deviance for each model

Table 3 Best models testing the effects of habitat variables and breeding parameters on clustered nesting in Eurasian Bitterns

\begin{tabular}{lllrr}
\hline Variables & Parameter estimate & SE & \multicolumn{1}{l}{$F$} & $P$ value \\
\hline Model 1 & & & & \\
NEW & 0.8395 & 0.3185 & 2.64 & 0.1079 \\
PROARE & 3.2831 & 0.2492 & 13.23 & 0.0005 \\
CARP & 1.5576 & 0.3023 & 5.15 & 0.0025 \\
Model 2 & & & & \\
EGGDATE & 1.4813 & 0.2019 & 7.34 & 0.0082 \\
MALE & 4.3508 & 0.2150 & 20.23 & $<0.0001$ \\
\hline
\end{tabular}

Table 4 Mean and standard deviations (SD) of habitat variables measured at single $(n=61)$ and clumped nests $(n=78)$ of the Eurasian Bittern

\begin{tabular}{lrrrrr}
\hline Variable & \multicolumn{2}{l}{ Single nests } & & \multicolumn{2}{c}{ Clumped nests } \\
\cline { 2 - 3 } \cline { 6 - 7 } & Mean & \pm SD & & Mean & \pm SD \\
\hline WATER (cm) & 45.1 & 15.41 & & 44.2 & 18.27 \\
OLD $(n)$ & 16.7 & 16.35 & & 20.5 & 13.44 \\
NEW $(n)$ & 8.4 & 10.02 & & 12.1 & 11.43 \\
DISTOW (m) & 27.7 & 22.08 & & 32.8 & 23.86 \\
DISTDYKE (m) & 30.7 & 28.64 & & 29.5 & 27.51 \\
PROARE (proportion) & 2.8 & 3.86 & & 1.4 & 1.07 \\
\hline
\end{tabular}

out in the UK, which found that the male's home-range encompassed on average $30 \%$ open water and $48 \%$ reed edge (Gilbert et al. 2005b). The lack of influence of other microhabitat parameters on nest clumping is due to stable nest preferences within a particular patch of emergent vegetation (Polak et al. 2008). The remaining micro- and macrohabitat parameters (water depth, number of new and old reed stems, distance to the dyke and distance to open water) were the same for single and clumped nests. Some habitat variables that affect the selection of nesting

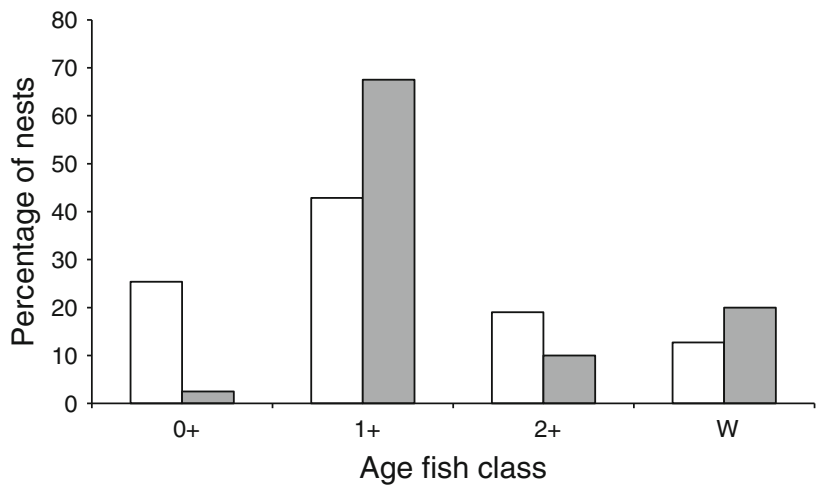

Fig. 2 Percentage of single (white columns, $n=63$ ) and clumped (grey columns, $n=80$ ) nests of Eurasian Bittern in ponds with three Common Carp year classes: young $(0+)$, medium $(1+)$ and old $(2+)$; and wild ponds $(W)$

positions, regardless of female status, appear to be crucial for Eurasian Bittern females (see Adamo et al. 2004; Gilbert et al. 2005a; Polak et al. 2008).

Besides the anti-predator role of habitat components (Polak 2007), the most important factor causing daily losses of Eurasian Bittern chicks was starvation (Gilbert et al. 2007). This could have been due to poor food availability (mainly a lack of fish) or poor weather conditions. In a specific habitat type like fishpond complexes, an important factor related to food resources is the Common Carp year-class. This study shows that females readily nested in clusters around ponds with Common Carp of the second year-class (1); this category of fish weight is suitable as food for Eurasian Bittern chicks (Polak 2007). Ponds with Common Carp in the first year-class (0) had a negative effect on clustering, probably because of the very small weight of the fish. Ponds with the third category of Common Carp (2) are also unattractive, since the fish have grown too large to be eaten by either chicks or adults. Moreover, ponds stocked with older cohorts of Common 
Carp are unsuitable for breeding amphibians (Kloskowski 2009), another of the Eurasian Bittern's prey items (Polak 2007; White et al. 2006).

In the present study, solitary females started laying eggs 6 days earlier than clumped females. The decision of secondary females (with a lower status in the polygynous system) to form a cluster could be due mainly to the existence of appropriate habitat components and food resources. A review of data from 28 bird species shows that a median interval of 8.6 days was found between the laying times of primary and secondary females (Slagsvold and Lifjeld 1994). Eurasian Bittern females established themselves earlier in the territories of males that started booming early and with a high vocalisation rate (Polak 2006). It is possible that males monopolising the best territories could be first to attract a mate early in the season, and would then be more likely to attract further females. Data from a French study suggest that boom length is likely to reflect a male's body condition and habitat quality (Poulin and Lefebvre 2003a, b). But no correlation between booming parameters and harem size has been found (Polak 2006).

Females of polygynous species may incur potential costs because they compete for territorial resources like food and appropriate nest-sites (Slagsvold and Lifjeld 1994; Forstmeier et al. 2001; Qvarnström et al. 2003). However, because of the good and stable food resources in the population studied, the nest success of clumped females was similar to that of single females. A few authors have found no differences in breeding parameters between females of different mating status (Petit 1991; Bensch 1996; Grønstøl 2003). Female Eurasian Bitterns nesting in clusters do not have to compete for a male contribution to feeding the young and may select this form of nesting as the best breeding strategy (a combination of male and territorial quality), especially if polygynous males offer better breeding and feeding grounds. The difference found in our study between single and clumped nests with respect to male presence confirms the attraction of male territories. We also wanted to know whether females could detect each other in the clusters (Dyrcz 1986; Bensch and Hasselquist 1992; Slagsvold and Lifjeld 1994; Qvarnström et al. 2003). The distance between the nests in Eurasian Bittern clusters was relatively small, making it possible for females to discover their mating status.

Our study shows that Eurasian Bitterns are quite flexible, selecting nesting and feeding grounds according to the distribution of suitable resources, and that individuals from populations breeding under different ecological situations can choose different breeding strategies. The most important aspects of clumped nesting are the appropriate proportion of macrohabitats in which a female can find rich food resources (fish stock category) and suitable nest-sites. Knowledge of the Eurasian Bittern's optimal habitat requirements can provide useful guidelines for future conservation projects involving this vulnerable species.

Acknowledgments We would like to thank everyone who helped with the fieldwork, especially M. Gąska, J. Kloskowski, J. Krogulec, M. Nieoczym, E. Zębek, R. Kuropieska and M. Szaniawska. The study was in compliance with current Polish Law and was permitted by the Local Ethical Commission and the Ministry of the Environment.

Open Access This article is distributed under the terms of the Creative Commons Attribution License which permits any use, distribution, and reproduction in any medium, provided the original author(s) and the source are credited.

\section{References}

Adamo MC, Puglisi L, Baldaccini NE (2004) Factors affecting bittern Botaurus stellaris distribution in a Mediterranean wetland. Bird Conserv Int 14:153-164

Bensch S (1996) Female mating status and reproductive success in the great reed warbler: is there a potential cost of polygyny that requires compensation? J Anim Biol 65:283-296

Bensch S, Hasselquist D (1992) Evidence for active female choice in a polygynous warbler. Anim Behav 44:301-311

Burnham KP, Anderson DR, Huyvaert KP (2011) AIC model selection and multimodel influence in behaviour ecology: some background, observations and comparisons. Behav Ecol Sociobiol 65:23-35

Cramp S, Simmons KEL (1977) The birds of the western Palearctic, vol I. Oxford University Press, Oxford

Demongin L, Dmitrenok M, Bretagnolle V (2007) Determining great bittern Botaurus stellaris laying date from egg and chick biometrics. Bird Study 54:54-60

Dmitrenok M, Demongin L, Zhurauliov D (2005) Three cases of replacement clutches in the great bittern Botaurus stellaris. Ardea 93:271-274

Dyrcz A (1986) Factors affecting facultative polygyny and breeding results in the great reed warbler (Acrocephalus arundinaceus). J Ornithol 127:447-461

Dyrcz A, Zdunek W (1993) Breeding ecology of the aquatic warbler Acrocephalus paludicola on the Biebrza marshes, northeast Poland. Ibis 135:181-189

Forstmeier W, Kuijper DPJ, Leisler B (2001) Polygyny in the dusky warbler, Phylloscopus fuscatus: the importance of female qualities. Anim Behav 62:1097-1108

Gauckler VA, Kraus M (1965) Zur Brutbiologie der Grossen Rohrdommel (Botaurus stellaris). Vogelwelt 86:129-145

Gilbert G, Tyler GA, Smith KW (2003) Nestling diet and fish preference of bitterns Botaurus stellaris in Britain. Ardea 91:35-44

Gilbert G, Tyler GA, Dunn CJ, Smith KW (2005a) Nesting habitat selection by bitterns in Britain and the implications for wetland management. Biol Conserv 124:547-553

Gilbert G, Tyler G, Smith KW (2005b) Behaviour, home-range size and habitat use by male great bittern Botaurus stellaris in Britain. Ibis 147:533-543

Gilbert G, Tyler GA, Dunn CJ, Ratcliffe N, Smith KW (2007) The influence of habitat management on the breeding success of the great bittern Botaurus stellaris in Britain. Ibis 149:53-66

Grønstøl GB (2003) Mate-sharing costs in polygynous northern lapwings Vanellus vanellus. Ibis 145:203-211

Jiguet F, Arroyo B, Bretagnolle V (2000) Lek mating systems: a case study in the little bustard Tetrax tetrax. Behav Proc 51:63-82 
Kenward RE (1987) Wildlife radio-tagging: equipment, field techniques and data analysis. Academic, London

Klejdus J (2007) Notes on breeding biology and behaviour of the great bittern (Botaurus stellaris) on the Śumickỳ upper fishpond in 2001-2007. Sylvia 43:139-153

Kloskowski J (2009) Size-structured effects of common carp on reproduction of pond-breeding amphibians. Hydrobiologia 635:205-213

Kushlan JA, Hafner H (2000) Heron conservation. Academic, London Mallord JW, Tyler GA, Gilbert G, Smith KW (2000) The first case of successful double brooding in the great bittern Botaurus stellaris. Ibis 142:672-675

Moreno J, Veiga JP, Romasanta M, Sanchez S (2002) Effects of maternal quality and mating status on female reproductive success in the polygynous spotless starling. Anim Behav 64:197-206

Ostfeld RS (1987) On the distinction between female defense and resource defense polygyny. Oikos 48:238-240

Petit LJ (1991) Experimentally induced polygyny in a monogamous bird species: prothonotary warblers and the polygyny threshold. Behav Ecol Sociobiol 29:177-187

Polak M (2006) Booming activity of male Bitterns Botaurus stellaris in relation to reproductive cycle and harem size. Ornis Fenn $83: 27-33$

Polak M (2007) Food of nestling great bitterns Botaurus stellaris at fishpond complexes in eastern Poland. Bird Study 54:280-283

Polak M, Kasprzykowski Z (2009) Numbers and density of the bittern Botaurus stellaris on selected fishponds in the Lublin and Podlasie Południowe regions. Notatki Ornitol 50:155-164

Polak M, Kasprzykowski Z (2010) Reproduction parameters of the great bittern Botaurus stellaris in the fish ponds of eastern Poland. Acta Ornithol 45:75-81
Polak M, Kasprzykowski Z, Kucharczyk M (2008) Micro-habitat nest preferences of the great bittern, Botaurus stellaris, on fishponds in central-eastern Poland. Ann Zool Fenn 45:102-108

Poulin B, Lefebvre G (2003a) Optimal sampling of booming bitterns Botaurus stellaris. Ornis Fenn 80:11-20

Poulin B, Lefebvre G (2003b) Variation in booming among great bitterns Botaurus stellaris in the Camargue, France. Ardea 91:177-182

Poulin B, Lefebvre G, Mathevet R (2005) Habitat selection by booming bitterns Botaurus stellaris in French Mediterranean reed-beds. Oryx 39:265-274

Puglisi L, Bretagnolle V (2005) Breeding biology of the bittern. Waterbirds 28:392-398

Puglisi L, Adamo C, Baldaccini NE (2003) Spatial behaviour of radio-tagged Eurasian bitterns Botaurus stellaris. Avian Sci 3:133-143

Qvarnström A, Sheldon BC, Pärt T, Gustafsson L (2003) Male ornamentation, timing of breeding, and cost of polygyny in the collared flycatcher. Behav Ecol 14:68-73

Slagsvold T, Lifjeld JT (1994) Polygyny in birds: the role of competition between females for male parental care. Am Nat 143:59-94

Statsoft Inc (2011) Statistica for Windows (data analysis system) version 9. www.statsoft.com

Tyler GA, Smith KW, Burges DJ (1998) Reedbed management and breeding bitterns Botaurus stellaris in the UK. Biol Conserv $86: 257-266$

Verner J, Willson MF (1966) The influence of habitats on mating systems of North American passerine birds. Ecology 47:143-147

Voisin C (1991) The herons of Europe. Poyser, London

White G, Purps J, Alsbury S (2006) The bittern in Europe: a guide to species and habitat management. RSPB, Sandy 